\title{
FPSO collision local damage and ultimate longitudinal bending strength analyses
}

\author{
Jorge L. Martinez ${ }^{\text {(D) , Julio C.R. Cyrino }}{ }^{\text {(D) }}$, Murilo A. Vaz ${ }^{a *}$ \\ a Programa de Engenharia Oceânica - Universidade Federal do Rio de Janeiro (UFRJ), Rio de Janeiro, RJ, Brasil. \\ E-mail: jlfernandez@oceanica.ufrj.br, julio@oceanica.ufrj.br, murilo@oceanica.ufrj.br \\ * Corresponding author
}

https://doi.org/10.1590/1679-78255952

\begin{abstract}
In offshore oil \&gas production there is a large concentration of platforms in a limited area of the sea, with the consequent increase of vessel traffic in the region. Platform supply vessels (PSVs), shuttle tankers and maintenance and safety units operate very close to these production platforms, creating a propitious scenario for collisions. Thus, the risk of collision between vessels and platforms has significantly increased, causing concern from the point of view of life loss, material damage and marine environment degradation. It is important to adequately design the structures and to predict the effects of accidents on the involved vessels. In the structural analysis of collision, geometric and material nonlinearities must be considered, as well as the striking ship velocity, the vessels draft difference, among other variables. In this work, the collision of a platform supply vessel with a single-hull Floating Production Storage and Offloading (FPSO) platform is studied through numerical simulation using the ANSYS LS-DYNA computational system. Damage is locally characterized by the collision force on the FPSO hull and the depth of penetration (displacement). In addition, it is also shown the energy absorption capacity of each type of structural element for the collision scenarios studied and a criterion is proposed to determine which structural element group should receive more attention in the design phase in order to reduce the effects of a collision. Both the longitudinal strengths of the intact FPSO as well as the remainder after collision are evaluated by assessing the bending moment versus curvature curves. It is observed that a single-hull FPSO platform with the thicknesses of the structural elements maintained unchanged in the conversion of the original oil tanker (VLCC) shows a significant ultimate longitudinal strength even after collision of a larger support vessel at higher velocity than recommended by the IACS rule.
\end{abstract}

\section{Keywords:}

Ship collision, Crashworthiness, Finite Element Model, Bending Moment, Ultimate Longitudinal Strength.

\section{Graphical Abstract}
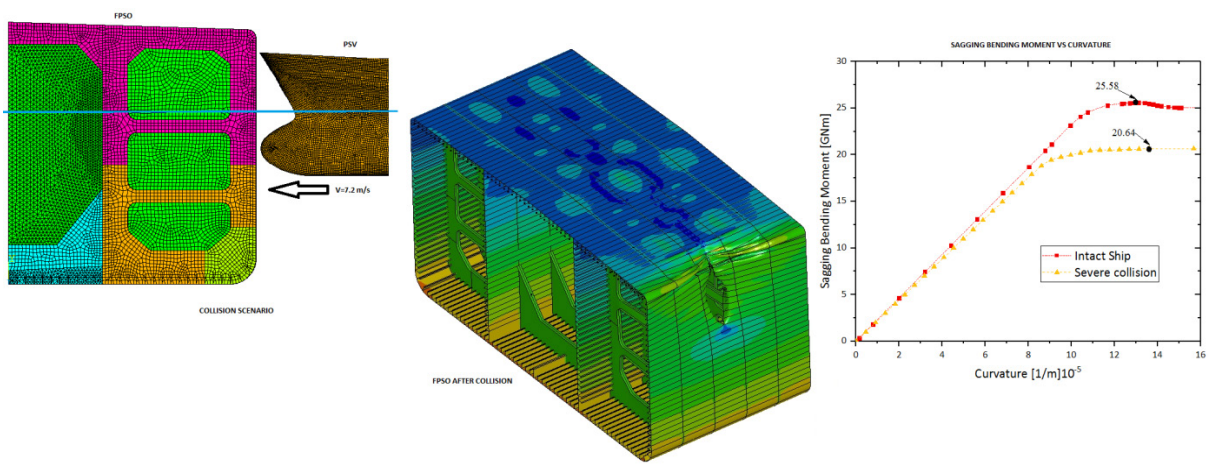


\section{INTRODUCTION}

The collision between ships, or a vessel with an offshore platform, is capable of compromising the stability and structural integrity of both structures, requiring withdrawal from operation for repair or even causing total loss. In both cases, there is concern about the safety and preservation of human lives and the great risk of marine environment contamination, as well as the enormous material damage. When different types of vessels approach a production platform to execute services or support, there is an intrinsic high potential risk of collision. Safety and Shipping Review (2017) reports that between 2007 and 2016 there was a total of 72 and 244 ships with total loss due to collision and strandings accidents, respectively. Continuous advances in international shipping standards, coupled with efforts to train crews and the increasing sophistication of equipment on board to assist the crew, have greatly contributed to reducing the number of accidents in recent years, but unfortunately these events still happen. Even in the case of severe damage, it is necessary to maintain sufficient residual strength of the structure to ensure its integrity and to allow navigation or operation until repair is carried out.

Collision simulation models are important at the design stage to ensure that the most vulnerable structural parts to this type of accident can be properly dimensioned or protected. In addition, these models are also useful to analyse a damaged structure and to indicate which measures should be taken before permanent repair. This article analyses the ultimate residual strength of a single hull FPSO type platform subjected to a collision from a PSV. The damage produced by the collision is determined by a finite element model simulation of the accident, showing that the procedure preconized by the IACS, which adopts an idealized damage for the calculation of the ultimate residual strength, can yield significant differences. To achieve the research objectives, a methodology is developed in this paper to simulate the ship collision and its effects on the overall strength of the struck vessel, based on known parameters such as vessel geometry, velocities, added masses, drafts, material mechanical properties as failure criteria. The proposed methodology is able to estimate the local structural response indicating displacements, deformations, fracture of elements and absorbed energy in the impact. It also allows the prediction of the overall effect on the structure of the struck ship (FPSO) by comparing the longitudinal bending moment versus curvature, before and after the collision.

First, the proposed numerical model to simulate collision is validated by comparing the collision force versus the penetration depth and the absorbed energy versus penetration, with results from experimental tests performed by Wevers and Vredeveldt (1999). Next, several PSV - FPSO collision scenarios are presented: four differences of vessels drafts, collision on and between web frames and two PSV initial velocities. The strain energies absorbed by groups of structural elements are used for local damage analysis. A criterion to indicate which group of elements is more likely to suffer greater deformations during any collision scenario is proposed, helping to improve the structure design. Additionally, a PSV with larger mass and higher initial velocity is also considered as one of the collision scenarios. In the numerical simulation of the collision the problem is considered as purely structural, where both vessels are discretized by finite element meshes using version 16.0 of the ANSYS LS-DYNA program for explicit transient analysis with geometric and material nonlinearities. Water ingress and cargo spill that may occur due to side shell plating fracture were not taken into account in this study for simplicity. Finally, with the assessed damage from the collision analyses the ultimate residual strengths for global longitudinal bending are also numerically evaluated for selected cases of damaged FPSO.

\section{LITERATURE REVIEW}

Minorsky's (1959) pioneer work was motivated by the new projects with nuclear propulsion plants, where the greatest concern was to avoid leakage of radioactive material. The validation of analytical and numerical models with experimental tests in scale models has also been performed (Törnqvist, 2003; Ehlers et al. 2008; Ehlers, 2011; Hogström, 2012). To understand and analyze the phenomenon and the response of ship and platform structures during accidents, collision and stranding experiments have been conducted in full and approximated scales, by Woisin (1979), Carlebur (1995), Sterndorff (1996), and Wevers and Vredeveldt (1999). Numerical and analytical models were also validated, comparing the results obtained from these models with those from experimental tests in laboratories with typical ship and platform panel models. Kitamura (2002), Prabowo et al. (2016), Hagen (2018) and Ozguc (2019) developed numerical models to simulate a diverse frame of collision and stranding accident events and characterized the final structure damages. The fracture location and time in a numerical collision simulation is highly dependent on the failure criterion employed. Calle and Alves (2015) presented a comprehensive review of fracture models typically employed in ship collision simulations. Martinez et al. (2017) recently presented a methodology based on the 
mechanics of continuous damage applied to the collision of vessels, obtaining satisfactory results compared to those obtained experimentally.

A significant part of the current research has focused on improving the methodology for collision and stranding analyses and the accuracy of failure criteria for the determination of damage caused to the hull structures. Another line of research that stands out is the determination of the ultimate longitudinal bending residual strength for damaged ships. In this sense, Luís et al. (2007) studied the longitudinal strength of two double hull Suezmax tankers after collision and stranding. The calculations were performed using Smith's simplified method and the damage was simulated by removing the damaged elements from the ship's middle section. It was concluded that the residual strength is dependent on the position and geometry of the damage. The residual strength of three double hull oil tankers was investigated by Hussein and Guedes Soares (2009), different scenarios of side and bottom damages were considered to define a lower strength limit. A design modification was suggested, expressed by increasing the deck thickness to compensate the ultimate strength loss due to eventual collision damage.

The ultimate longitudinal strength of a Panamax bulk carrier in intact and damaged conditions was investigated by Yamada and Ogawa (2011) and Yamada (2014) using the finite element program LS-DYNA and the simplified Smith's method. The ultimate strength in the damaged condition was estimated assuming a collision on mid-ship where the damage was artificially created. It was demonstrated that the ultimate longitudinal strength determined by the finite element model and simplified analyses for both intact and damaged structures showed a good agreement, although some discrepancies could be identified. Paik et al. (2012) created a damage index defined as a function of certain parameters, as for example the location and extent of the damage. The residual strengths for a small number of scenarios are calculated, and then a diagram relating the residual strengths to the damage indexes can be drawn. In order to demonstrate the applicability of the method, the ultimate longitudinal strength versus stranding damage index for double-hull VLCC tankers, Suezmax, Aframax and Panamax types was determined. Kim et al. (2014) developed a similar diagram, employing a damage index, taking into account corrosion wear over time. The investigation was applied to a vessel subjected to stranding damage, whose corrosion wear was established by a time-dependent model. The ultimate residual strength versus time-dependent and original damage indexes were compared and showed differences of up to $24.7 \%$ in the residual strength for a considered time of 25 years.

\section{FINITE ELEMENT ANALYSIS OF SHIP COLLISION}

\subsection{Validation of the Numerical Collision Model}

The Centre for Mechanical Engineering from the Netherlands Organisation for Applied Scientific Research (CMC-TNO) conducted a series of four collision experiments within the scope of an international cooperation between Japanese, Dutch and German partners. The results of one of these experiments are reported in Lehmann and Peschmann (2002). The struck ship model dimensions were based on a double hull tanker with approximately 30,000 deadweight tonnage (DWT). The model constructed with grade-A structural steel represented part of the central tank side, with a scale of 1:3, with total height $4.2 \mathrm{~m}$ and length $7.5 \mathrm{~m}$. The side thickness was $5 \mathrm{~mm}$ and the thicknesses of the bottom and deck plating were $10 \mathrm{~mm}$, the transversal stiffeners were flat bars with $100 \times 5 \mathrm{~mm}$. In the bow area of a coVAlidmmon fishing vessel a bulb was adapted and filled with concrete to increase its rigidity. The collision was performed perpendicular to the model side with a velocity of $2.55 \mathrm{~m} / \mathrm{s}$. In Figure 1, the geometry and dimensions of the structural frame are presented, as well as the geometry of the rigid indenter used in the experiment. The Figures 1a-c were kindly provided by Prof. Sören Ehlers from the Hamburg University of Technology. 
(a)

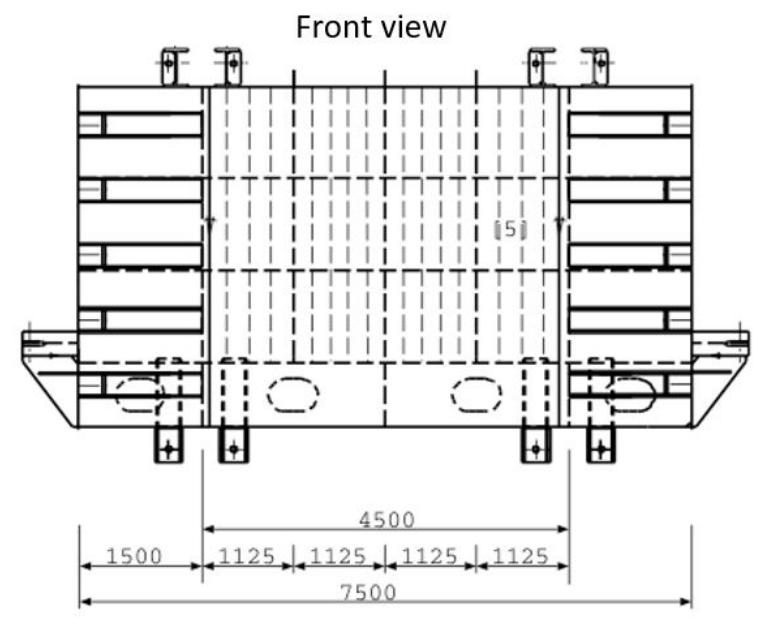

(c)

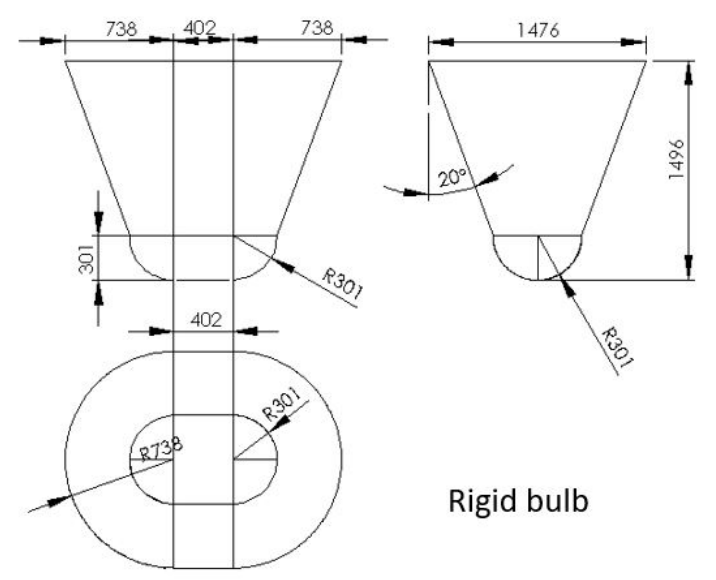

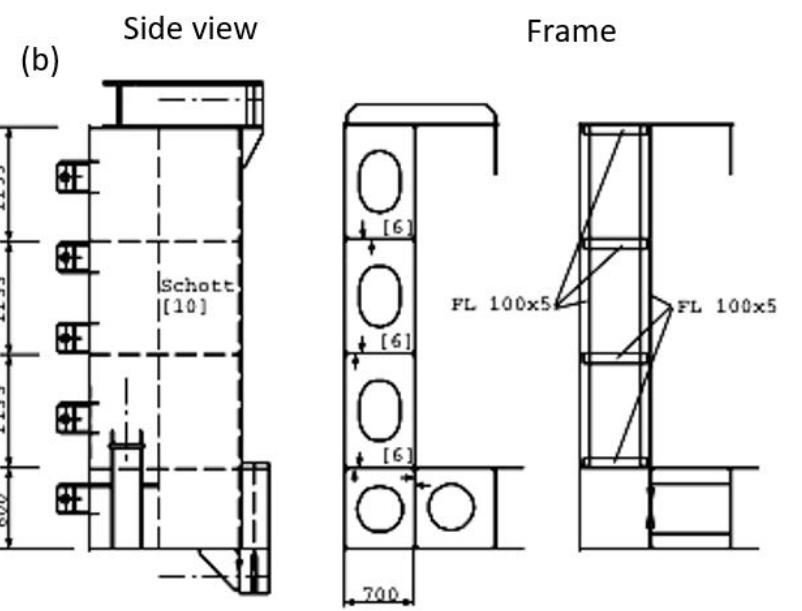

(d)

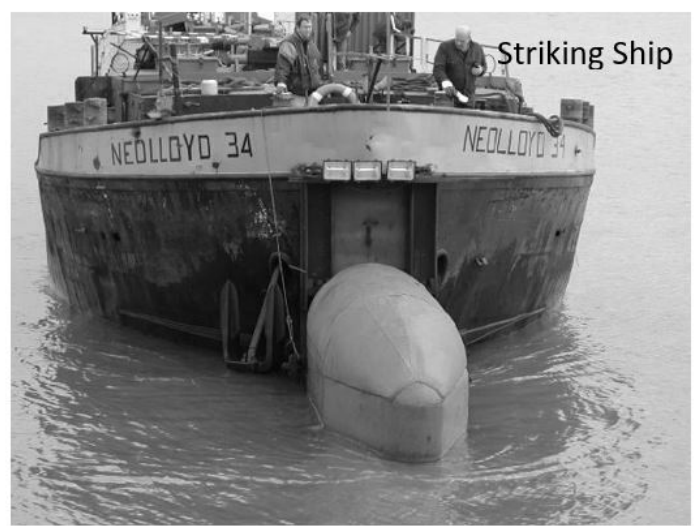

Figure 1: The geometries for the collision test (a) View front of struck ship (b) Construction of the sidewall model cuts (c) The bulb of the stricking ship (d) The bulb of the striking ship is mounted on the bow (Törnqvist, 2003)

The true stress-strain curve of the material was obtained in Ehlers et al. (2008). The material behavior was assumed to be elastic-plastic with isotropic strain hardening and was represented by a power law in the form $\sigma=K \varepsilon^{\mathrm{n}}$, with strength coefficient $\mathrm{K}=730 \mathrm{MPa}$ and strain hardening index $\mathrm{n}=0.20$. The yield stress, Young's Modulus and Poisson's coefficient were respectively $284 \mathrm{MPa}, 206 \mathrm{GPa}$ and 0.3. Implementation of those values was performed for material model 123(*MAT_MODIFIED_PIECEWISE_LINEAR_PLASTICITY).

In the finite element model it was only considered the side of the struck ship in the collision region. The structural members of the side model were discretized as shown in Figure 2, and the striking vessel was reduced to its bulb and considered as a rigid structure. The bulb was modeled rigid, material model 20 (*MAT_RIGID). In the numerical-experimental correlation study several simulations were performed to select the most appropriate parameters values for the collision analyses, as well as to identify their relative influences on the results. In the experimental test the results are expressed in terms of the measured collision force versus depth of penetration of the striking vessel on the side of the struck vessel and the absorbed energy versus penetration. 

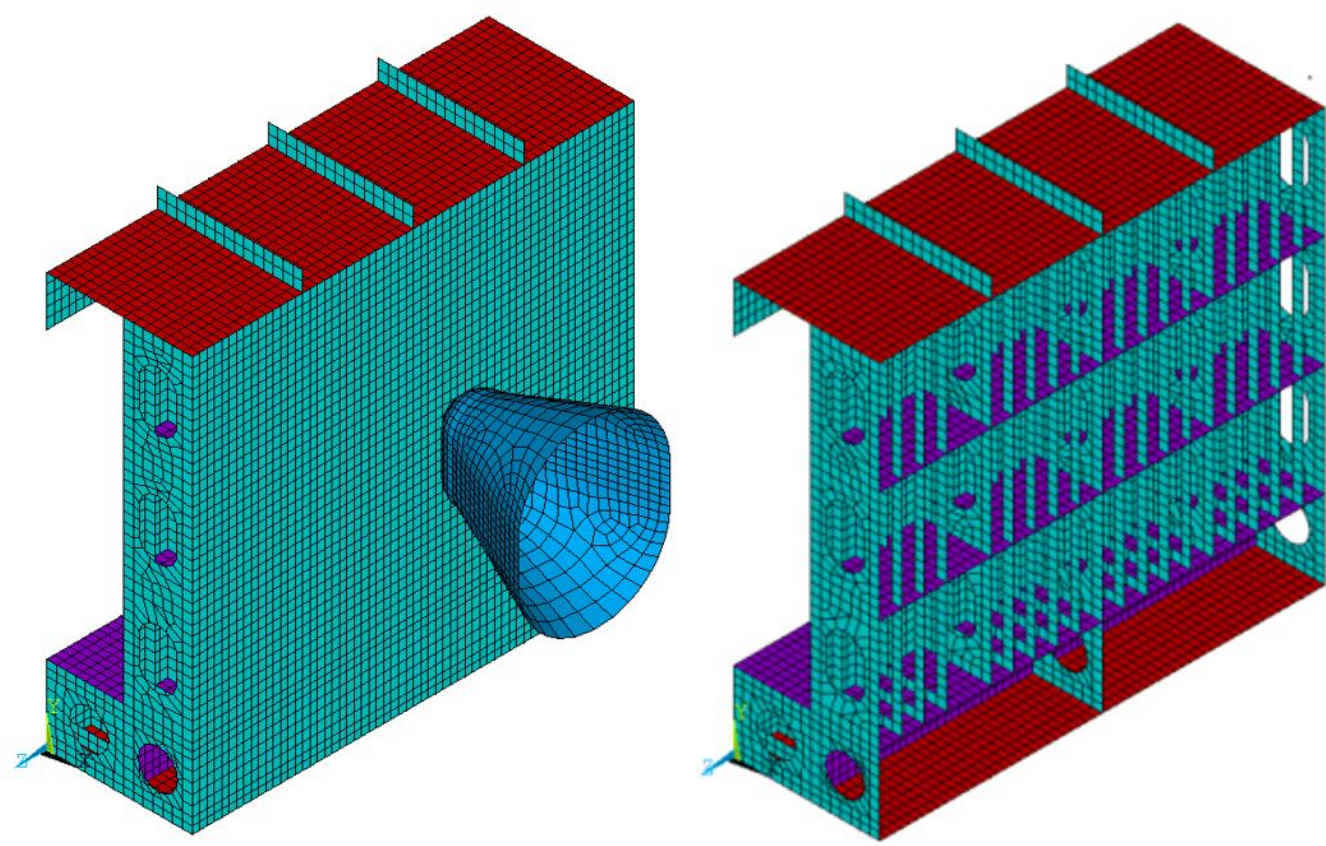

Figure 2: Finite element model using mesh size $100 \mathrm{~mm}$

The parameters considered were: geometric imperfections, type of element, friction coefficient, boundary conditions and mesh refinement associated with failure criteria. Semi-waves in the longitudinal direction between web frames and in the transverse direction between longitudinal stiffeners were adopted as geometric imperfections, with maximum amplitudes stipulated by DNVGL-OS-C401, Ch2. Sec. 2E (DNV GL, 2017) specification. Nonetheless, the comparison of the results with and without imperfection confirmed that the consideration of the initial geometrical imperfections is not important in this application. The effect of initial imperfection in subsequent FPSO ultimate longitudinal bending strength analysis will be investigated in next section. Belytschko-Tsayand and Belytschko-Wong-Chiang (including warping effects) shell elements, which are based on Mindlin-Reissner's theory, were used, and the only difference observed was that the former shell element was $8 \%$ faster. To evaluate the effect of friction coefficient on the response a parametric study was performed with values between 0.0 and 0.6 . In the analyses with a coefficient of friction between 0.3 and 0.6 the collision force presented a behavior close to the experimental curve, thus the value adopted for subsequent analyses was 0.3. Two types of boundary conditions were applied at the ends of the model (all nodes, including the nodes from the web frames): BC-1, where all nodes were considered embedded; BC-2, no translations and free rotations. The results with these boundary conditions did not show noticeable differences, thus BC-1 was used.

In the collision region finer meshes with elements dimensions equal to $25,35,50$ and $100 \mathrm{~mm}$ were used and a coarser mesh was considered elsewhere. For each of those meshes, Germanischer Lloyd (GL) (Vredeveldt and Feenstra, 2001), Peschmann (PE) (Peschmann, 2001) and equivalent plastic strain (SE) failure criteria were employed. The main expressions used in the GL and PE criteria are presented in Calle and Alves. (2015) [[Q1: Q1]] and Lehmann and Peschmann (2002). The equivalent plastic failure strain was assumed equal to 0.2. Figure 3 shows the error percentage curves in relation to the experimental results for the strain energy as a function of different element sizes for each damage criterion. As it can be observed, GL criterion presents the largest errors for all mesh sizes. The SE criterion shows errors slightly smaller than the PE criterion for meshes smaller than approximately $80 \mathrm{~mm}$, however, the latter shows little sensitivity in relation to the elements dimensions. The error percentage for the Peschmann criterion for element size between 25 and $100 \mathrm{~mm}$ was more regular and thus this criterion was selected.

In Figure 4 the collision force and the strain energy versus penetration depth curves for the experimental and the numerical analyses using three fracture criteria are shown. The mesh in the collision area was built with $25 \mathrm{~mm}$ long elements. Two important moments of the collision are characterized depicting force decays after peaks following fracture of external and internal hull structures. In between those peaks it is observed an increase of penetration with little force increase. In the numerical simulations the external hull fractures with lower penetrations and forces using GL and SE criteria and overall better experimental correlation is found with PE criterion. The three criteria predict the internal hull fracture before the experimental test. 


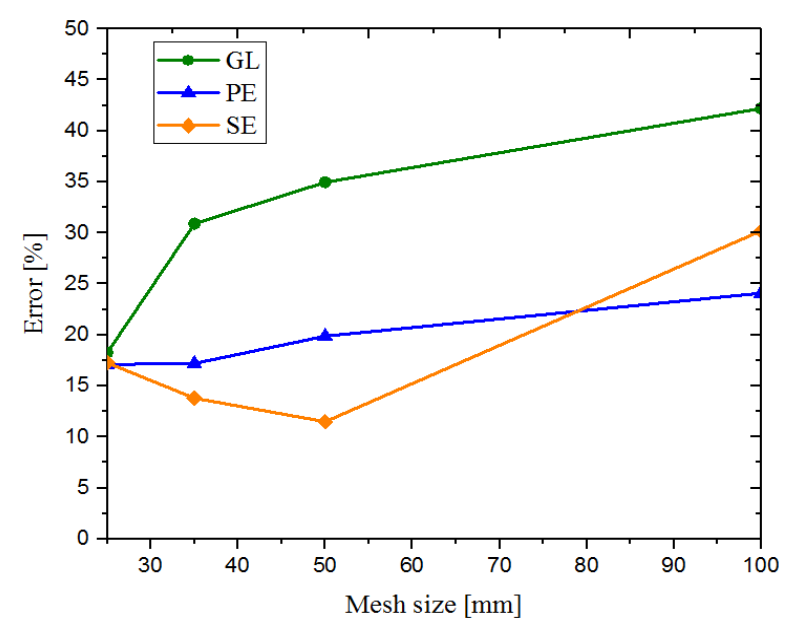

Figure 3: Absorbed energy error for each failure criterion versus element size

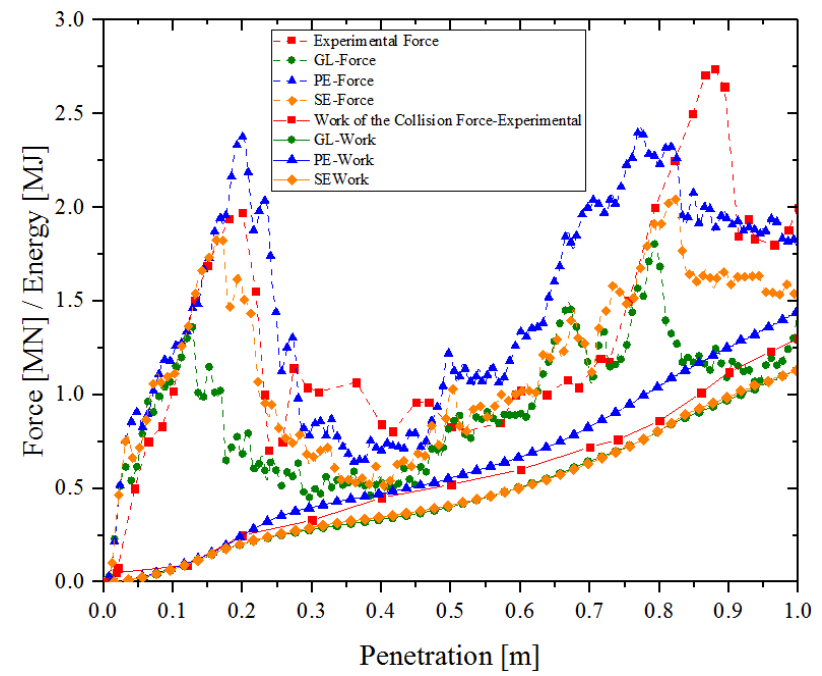

Figure 4: Results of the experimental test (Lehmann and Peschmann, 2002) and numerical simulations (25 mm elements) for different criteria

The PE fracture criterion was chosen as default for the further collision analyses, because it showed greater regularity in the strain energy error, independent of the mesh elements dimension (Figure 3).Therefore, for the purpose of collision analyses it is considered that the numerical model is validated.

\subsection{Numerical Simulation of PSV - FPSO Collision}

In this section, the methodology used in the collision simulation between FPSO and PSV is presented. The objective is to calculate the internal energy and damaged geometry of the FPSO hull for different collision scenarios, using the finite element code ANSYS LS-DYNA (ANSYS Inc, 2016), following considerations established for the validation of the numerical collision model. The main characteristics of the FPSO and PSV vessels used in the numerical simulations are presented in Table 1, and PE failure criterion is also assumed. The struck and striking vessels used in the numerical simulation were respectively a single hull Floating Production Storage and Offloading (FPSO) and a Platform Supply Vessel (PSV). When elaborating the numerical model the constructive dimensions of the FPSO ship were used, and data and drawings of the FPSO were obtained from Silva (2001). Figure 5 shows the FPSO mid-ship cross-section and main topology characteristics are specified together with the dimensions of the most important structural elements. The material used was ASTM A131 Gr DH32 steel with 315 MPa yield stress. The material used both for the FPSO and PSV is the shipbuilding steel DH-32 with $315 \mathrm{MPa}$ yield stress. The true stress-strain curve was obtained from Silva (2001). 
Table 1 Vessel's Characteristics.

\begin{tabular}{ccc}
\hline Characteristics & FPSO & PSV \\
\hline LPP $(\mathrm{m})$ & 320 & 70.16 \\
Beam $(\mathrm{m})$ & 54.5 & 14.67 \\
Depth $(\mathrm{m})$ & 27.8 & 6.07 \\
Max. draft(m) & 21.62 & 5.04 \\
Min. draft(m) & 7.00 & 3.01 \\
Light displacement (t) & 39150 & 3050 \\
Displacement (t) & 321903 & 6125 \\
Velocity of collision (m/s) & 0.0 & $1.8 / 3.6 / 7.2$ \\
Non-dimensional added mass (Surge) & - & 0.05 \\
Non-dimensional added mass (Sway) & - & 0.86 \\
Non-dimensional added mass (Yaw) & - & 0.21 \\
\hline
\end{tabular}

\begin{tabular}{|c|c|c|}
\hline \multicolumn{2}{|c|}{$\begin{array}{l}\text { TABELA DE LONGC TUDCRALS } \\
\text { OA ANTEPAPA LONCITUOINAL }\end{array}$} & \multirow{2}{*}{$\begin{array}{l}\text { TLAELA OE PLACA } \\
\text { ENTRE LONGITUOTNAIS } \\
\text { MO LNDO OA ANTEPARA }\end{array}$} \\
\hline & $d \times b_{f} \times t_{f} / t_{y}$ & \\
\hline 58 & $350 \times 100 \times 12 / 17 \mathrm{~L}$ & \multirow[b]{2}{*}{$\sim 20$} \\
\hline 57 & $350 \times 100 \times 12 / 17 \mathrm{~L}$ & \\
\hline 56 & $350 \times 100 \times 12 / 17 \mathrm{~L}$ & \multirow{8}{*}{$\sim 11$} \\
\hline 55 & $400 \times 100 \times 12 / 18 \mathrm{~L}$ & \\
\hline 54 & $400 \times 150 \times 11 / 18 \mathrm{~L}$ & \\
\hline 53 & $400 \times 150 \times 11 / 1 / B L$ & \\
\hline 52 & $530 \times 350 \times 14 / 30 \mathrm{~L}$ & \\
\hline 51 & $500 \times 150 \times 11 / 14 \mathrm{~L}$ & \\
\hline 50 & $500 \times 150 \times 11 / 14 \mathrm{~L}$ & \\
\hline 49 & $500 \times 150 \times 11 / 14 \mathrm{~L}$ & \\
\hline 48 & $500 \times 150 \times 11 / 16 \mathrm{~L}$ & \multirow{5}{*}{$\sim 14.5$} \\
\hline 47 & $550 \times 150 \times 11 / 16 \mathrm{~L}$ & \\
\hline 46 & $550 \times 150 \times 11 / 19 \mathrm{~L}$ & \\
\hline 45 & $550 \times 150 \times 11 / 19 \mathrm{~L}$ & \\
\hline 44 & $550 \times 150 \times 11 / 22 \mathrm{~L}$ & \\
\hline 43 & $550 \times 150 \times 11 / 25 \mathrm{~L}$ & \multirow{3}{*}{$\sim 16$} \\
\hline 42 & $550 \times 150 \times 11 / 28 \mathrm{~L}$ & \\
\hline 11 & $550 \times 150 \times 11 / 30 \mathrm{~L}$ & \\
\hline 10 & $650 \times 150 \times 11.5 / 22 \mathrm{~L}$ & \multirow{4}{*}{$\sim 17.5$} \\
\hline 39 & $850 \times 150 \times 11.5 / 22 L$ & \\
\hline 38 & $650 \times 150 \times 11.5 / 25 \mathrm{~L}$ & \\
\hline 37 & $650 \times 150 \times 11.5 / 25 \mathrm{~L}$ & \\
\hline 36 & $550 \times 150 \times 11.5 / 28 \mathrm{~L}$ & \multirow{3}{*}{$\sim 18.5$} \\
\hline 35 & $650 \times 150 \times 11.5 / 28 \mathrm{~L}$ & \\
\hline 34 & $650 \times 150 \times 11.5 / 30 \mathrm{~L}$ & \\
\hline 33 & $700 \times 150 \times 12 / 28 \mathrm{~L}$ & \multirow[b]{2}{*}{$\sim 19.5$} \\
\hline$\frac{32}{31}$ & $\frac{700 \times 150 \times 12 / 28 \mathrm{~L}}{700 \times 150 \times 12 / 30 \mathrm{~L}}$ & \\
\hline 30 & $760 \times 150 \times 16 / 28 \mathrm{~L}$ & \multirow{3}{*}{$\sim 22$} \\
\hline 29 & $700 \times 150 \times 12 / 35 \mathrm{~L}$ & \\
\hline 28 & $700 \times 150 \times 12 / 38 \mathrm{~L}$ & \\
\hline
\end{tabular}
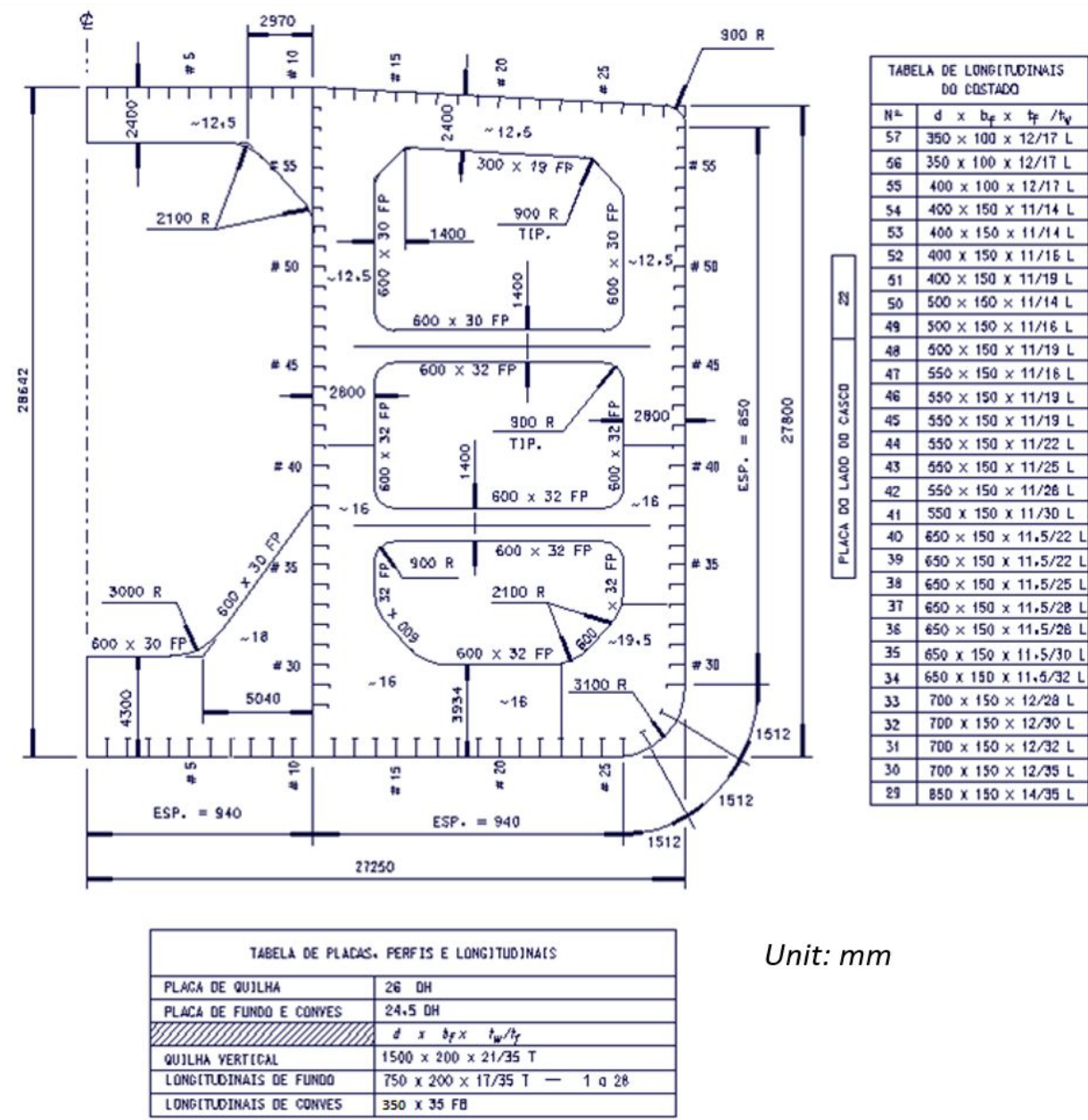

Unit: $\mathrm{mm}$

Figure 5: FPSO midship cross-section

Finite element model

The finite element numerical model was constructed with the same parameters, previously analyzed in the validation, and since Peschmann's failure criterion was used, the critical strain is calculated for all structural members. The fracture eof the element is considered when the calculated strain in the element exceeds the critical value. In Figure 3 it was shown that the error with the PE criterion for a mesh with 50 mm long elements was just slightly larger than the error for a $25 \mathrm{~mm}$ mesh. Thus, to save computational time, in the following applications $50 \mathrm{~mm}$ elements are used in the FPSO side area that contacts the PSV, and $350 \mathrm{~mm}$ elements are used elsewhere.

The PSV ship geometry was developed in the Maxsurf program, and the hull shape was exported to ANSYS / LS-DYNA. Only the PSV bow was considered in the analysis and the element used in the discretization was Shell 163, with rigid 
type material assuming that the striking ship bow is rigid (Zhang et al. (2004) and Pedersen and Zhang (1998)). For the striking ship model, besides the finite element mesh defining the bow geometry, it is necessary to include the vessel's inertia data, total mass considering additional mass, center of gravity and the initial velocity, in order to simulate the impact.

Due to the excessive computational time to perform the collision analyses, a model reduction was necessary without compromising the response. A top view of the reduced FPSO tank is shown in Figure 6a, which includes only five web frames plus extra fore and after spacings to introduce the boundary conditions, the model is then $31.8 \mathrm{~m}$ long. Figure $6 \mathrm{~b}$ shows a perspective view of the reduced region in the longitudinal direction. Due to the high transverse stiffness of the FPSO, a section in the longitudinal direction was also applied to the previous reduced model, as Figure $6 \mathrm{c}$ and Figure $6 \mathrm{~d}$ show. With this section appropriately far from the side, in this case, $11.0 \mathrm{~m}$, and with the application of suitable boundary conditions, the result of a collision analysis remains unchanged in relation to the original structure. Complete restriction of the nodes displacements in all directions for the end cross-sections and for the nodes in the longitudinal section of the web frames displacements were restricted and rotations allowed.

Another important issue is to include in the analysis the movements of the ships during collision. In the classic theory of the external dynamics of collision, ships are supposed to have only three degrees of freedom in the horizontal plane (Surge, Sway and Yaw), being Pitch, Heave and Roll effects disregarded because of their small influences. Liu et al. (2017) compared finite element collision simulations using two procedures. In the first method, the external dynamics was decoupled, using the analytical calculation of Pedersen and Zhang (1998), and the internal mechanics of the collision was performed with a finite element model. In the second method, the external dynamics was coupled by the simplified method of Pill and Tabri (2009) with the analysis of internal mechanics. With this comparison, Liu et al. (2017) concluded that the decoupled method provides sufficient precision to calculate the critical collision velocity used in design. Therefore, the decoupled method is considered in this article.

(a)

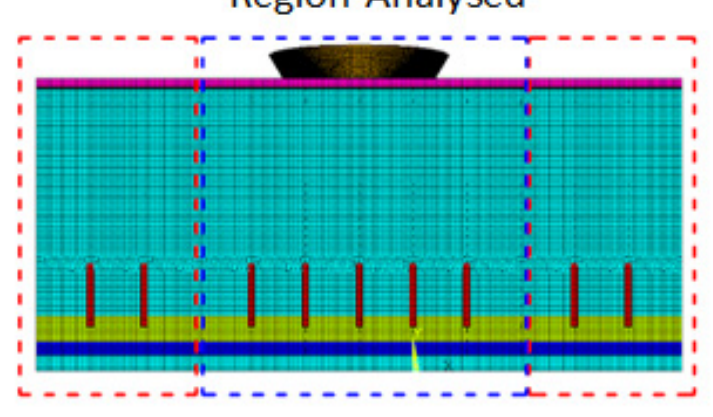

(c)

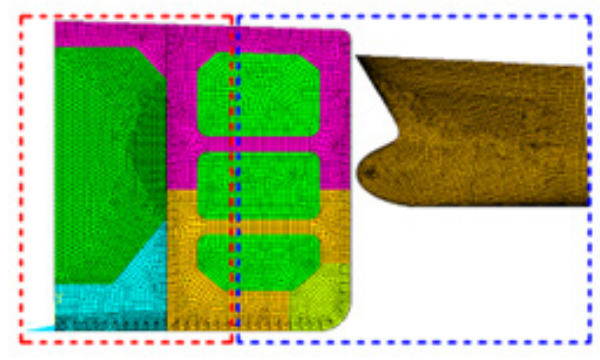

(b)

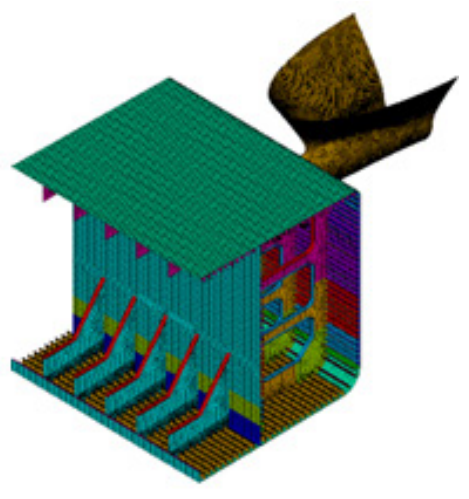

(d)

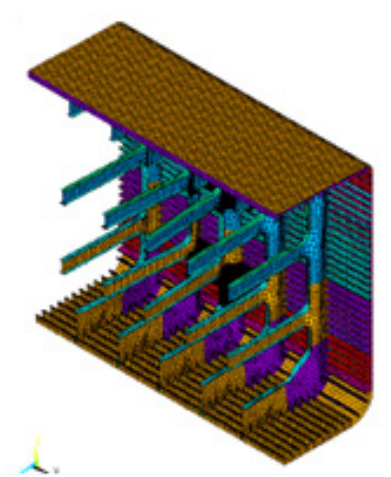

Figure 6: Reduction of the numerical model (a) Top view of the reduced FPSO tank (b) Perspective view of the reduced region in the longitudinal direction (c) Longitudinal view of reduced model (d) Final perspective view of the reduced FPSO

The collision scenarios

One of the important factors in the analysis of collision of floating bodies is their relative positioning, characterizing uncountable collision scenarios. In order to limit the number of cases to be studied, Zhang et al. (2004) proposed a procedure for determining four relative vertical positions, that is, different drafts $(\Delta T)$ between PSV and 
FPSO. These four values of draft differences are determined by Eqs. (1) to (4), in which the drafts $T_{1 \text { max }}, T_{2 \max }, T_{1 \text { min }}$ and $T_{2 \min }$ respectively correspond to the design and ballast condition drafts of the PSV and FPSO.

$$
\begin{aligned}
& \Delta T_{1}=T_{2 \max }-\frac{3 T_{1 \min }+T_{1 \max }}{4} \\
& \Delta T_{2}=T_{2 \max }-\frac{T_{1 \min }+3 T_{1 \max }}{4} \\
& \Delta T_{3}=\frac{T_{2 \min }+3 T_{2 \max }}{4}-T_{1 \max } \\
& \Delta T_{4}=\frac{3 T_{2 \min }+T_{2 \max }}{4}-T_{1 \max }
\end{aligned}
$$

From the characteristics given in Table 1, the values of drafts differences are:

$$
\Delta T_{1}=18.10 \mathrm{~m} ; \Delta T_{2}=17.09 \mathrm{~m} ; \Delta T_{3}=12.92 \mathrm{~m} ; \Delta T_{4}=5.62 \mathrm{~m} ;
$$

For the definition of collision scenarios, the contact position of the striking vessel (PSV) in the longitudinal direction of the struck ship (FPSO) must also be evaluated. In this paper it is assumed that the collision may occur at the midpoint between two FPSO web frames (BWF) or directly at the web frame (DWF). Another parameter that defines a collision scenario is the angle between the ships longitudinal planes (collision angle). In this article, the collision is assumed perpendicular. The velocity of the striking ship is also an important parameter to define the collision scenario. Thus, in summary the collision scenarios to be considered in the analyses are the following: BWF and DWF, PSV velocities equal to $1.8 \mathrm{~m} / \mathrm{s}$ and $3.6 \mathrm{~m} / \mathrm{s}$ and four different drafts differences, totaling sixteen scenarios. Additionally, due to the possibility of collision of larger ships, another simulation was carried out increasing the displacement and velocity of the aggressor ship respectively to $10,000 \mathrm{t}$ and $7.2 \mathrm{~m} / \mathrm{s}$, assuming only the BWF collision scenario with draft variation $\left(\ddot{\mathrm{AT}} \mathrm{T}_{1}\right)$.

\section{BWF cases results}

The bow of the striking ship is considered rigid compared to the structure of the struck ship's side, so most of the kinetic energy of the striking ship is consumed to damage the side structure of the struck ship and a less significant part of the energy is absorbed to displace the FPSO. Figure 7 shows the PSV penetration depth in the hull of the struck ship (FPSO) versus time, for a PSV initial velocity equal to $1.8 \mathrm{~m} / \mathrm{s}$. All curves are characterized by gradual penetration increase from zero to a maximum value followed by a decrease. The PSV velocity curves versus time are also shown in Figure 7. It is observed that the initial collision velocity is $1.8 \mathrm{~m} / \mathrm{s}$, and after a short time the ship velocity begins to decrease up to zero, and in sequence the velocity assumes negative values, that is, the PSV moves in the opposite direction. The negative velocity is due to the recovery of the developed elastic deformation. It can be observed in Figure 7 that the penetration reaches the maximum value at the same instant of time as the velocity reaches zero, then the penetration decreases and the velocity becomes negative, indicating the return of the vessel. No fracture was observed for this initial velocity.

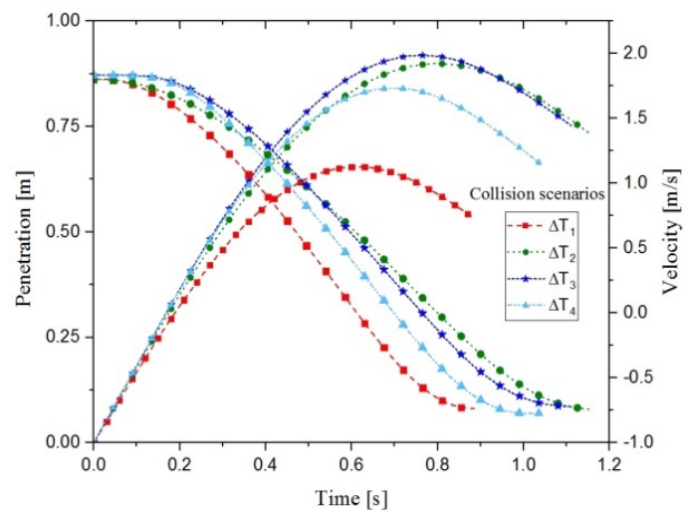

Figure 7: Depth of penetration / Velocity of PSV vs time for scenario BWF ( $v=1.8 \mathrm{~m} / \mathrm{s})$ 
The curves of Figure 8 show that for all draft differences $(\Delta T)$ the collision force increases with the elapsed time of collision, and after reaching a maximum value it decreases until it reaches zero. It can also be observed that the curves present small oscillations due to the loss of strength of some longitudinal reinforcements. For this reason, the instant of time when the force begins to decrease is not very well defined, but this occurs at the same time that the penetration is maximum and the velocity equals zero (Figure 7). It should be noted that this behavior occurs for all cases of $1.8 \mathrm{~m} / \mathrm{s}$ initial velocity because the FPSO hull does not fracture.

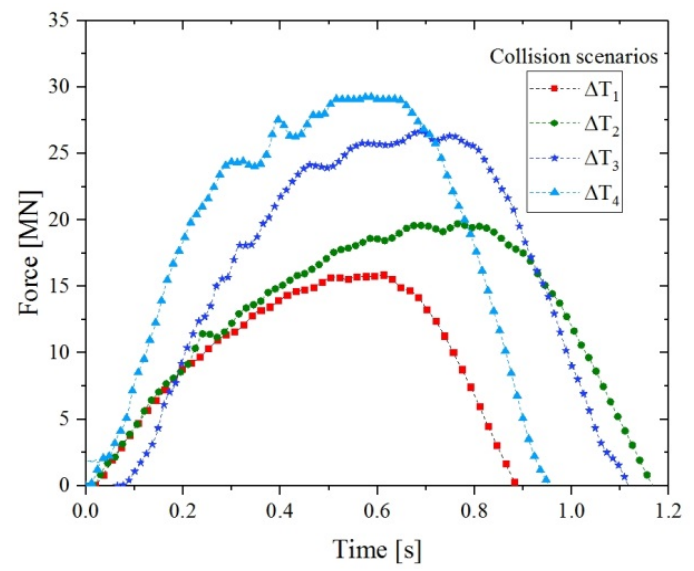

Figure 8: Collision force vs Time $(v=1.8 \mathrm{~m} / \mathrm{s})$ for scenario BWF

In the BWF scenario with a PSV initial velocity equal to $3.6 \mathrm{~m} / \mathrm{s}$, for draft differences $(\Delta T)$, there was a fracture of the FPSO hull and the collision loading curves versus time are shown in Figure 9. A similar behavior is observed, initially the force grows over time to a maximum load value and then there is a sudden load decrease, characterizing the FPSO hull fracture. Subsequently, a partial strength recovery occurs, represented by a force increase, and then the curve intercalates accentuated and mild oscillations, which respectively depict the fracture or loss of strength of web frames (most relevant structural elements) and longitudinal elements.

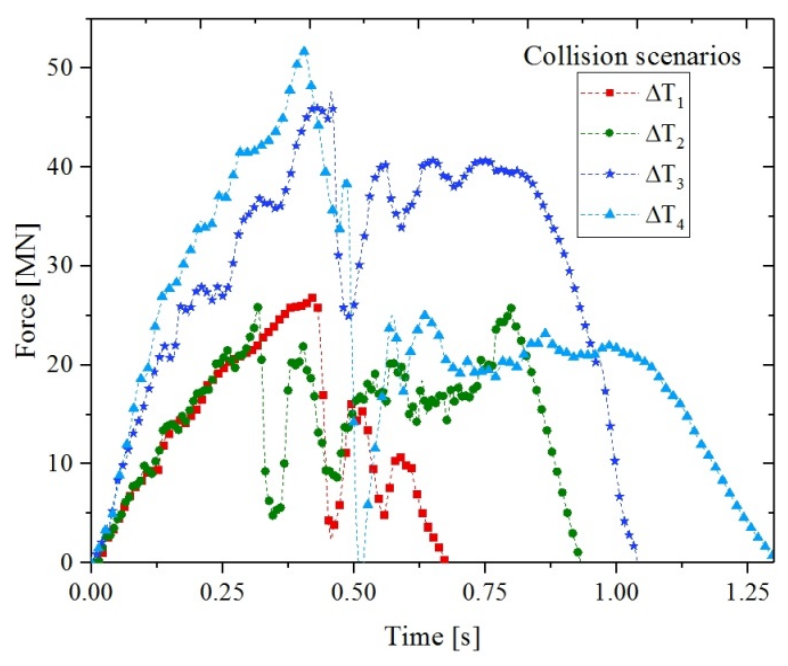

Figure 9: Collision force vs Time for scenario BWF $(v=3.6 \mathrm{~m} / \mathrm{s})$

For the BWF collision scenario with draft difference $\ddot{\mathrm{AT}} \mathrm{T}_{1}$ and PSV initial velocity $7.2 \mathrm{~m} / \mathrm{s}$, Figure 10 shows the penetration depth, the velocity of the striking ship and the penetration force versus time. It can be seen that the penetration curve gradually increases from zero to a maximum value of approximately $7.5 \mathrm{~m}$ and stays nearly constant. Since there was a severe damage of the FPSO hull, the PSV ship's bow is embedded in the FPSO hull and cannot move backwards. Due to the scale in Figure 10, it cannot be seen that the velocity at 1.69s is very small and it is just equal to zero at $1.79 \mathrm{~s}$, when the force is also equal to zero. The collision force close to $0.25 \mathrm{~s}$ undergoes a sudden decay, which corresponds to the beginning of the plating fracture and some of the FPSO longitudinal hull stiffeners. Afterwards, the penetration force grows and reaches its maximum value in $1.12 \mathrm{~s}$, and then it reduces reflecting loss of the hull 
strength in the region of the collision. At this point there is a change in the slope of penetration versus the time curve, that is, the penetration increases at a much lower rate.

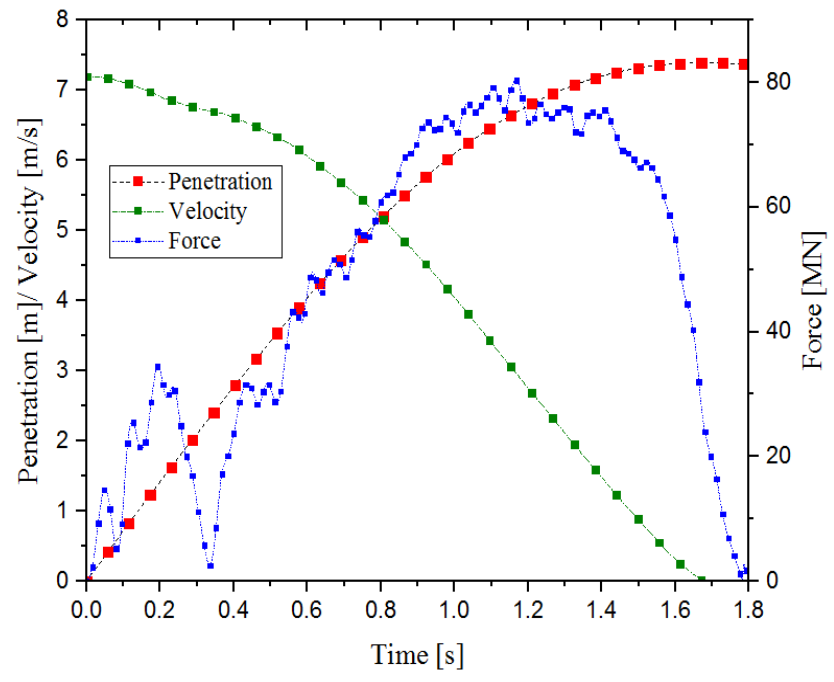

Figure 10: PSV penetration /velocity /collision force vs. Time for scenario BWF $(v=7.2 \mathrm{~m} / \mathrm{s})$

DWF cases results

Considering that in this case there was no fracture of the FPSO hull for the initial velocity of $1.8 \mathrm{~m} / \mathrm{s}$, it will not be shown the curves due to their similarities to the BWF case. The DWF scenarios with a PSV initial velocity equal to $3.6 \mathrm{~m} / \mathrm{s}$ produced fracture of the FPSO hull. The curves of Figure 11 show that initially the collision force increases with time, and small oscillations can also be observed due to the loss of longitudinal side strength. After a short time there is a strong drop in the load for all cases, meaning the hull fracture. At continuation the collision process exhibits a partial strength recovery, represented by a force increase, more expressive for case 2 . The curves throughout the process intercalate accentuated and mild oscillations, respectively indicating fracture or loss of strength of web frames and longitudinal elements, respectively.

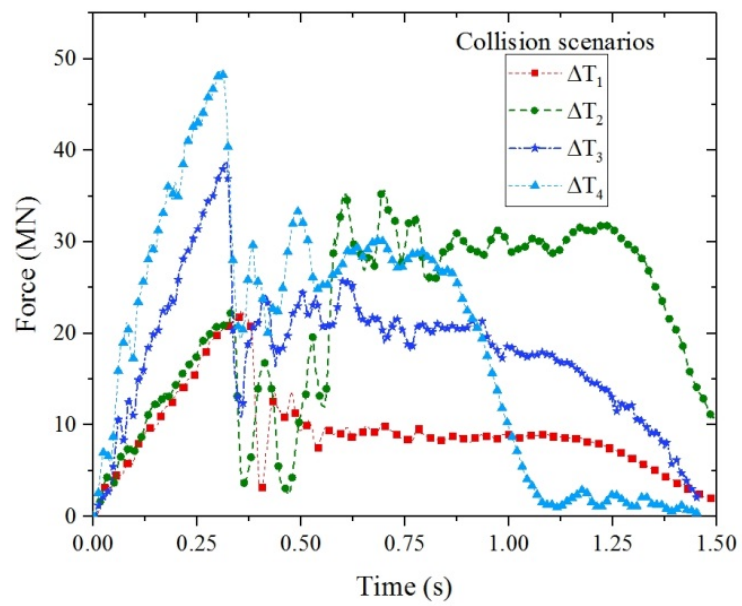

Figure 11: Collision force vs Time for scenario DWF $(v=3.6 \mathrm{~m} / \mathrm{s})$

Results of collision analysis in terms of energy

In order to have a comparison base for the numerical analyses results, the dissipated energy was calculated through the analytical model developed by Pedersen and Zhang (1998), and implemented using the Mathcad 14 Program. It should be emphasized that in this formulation the longitudinal positions of the striking ship are not considered in relation to the struck ship, therefore, there were only 4 scenarios considering different drafts for each velocity. For PSV with a displacement of $10,000 \mathrm{t}$ and velocity of $7.2 \mathrm{~m} / \mathrm{s}$ the energy was calculated only for the $\Delta T_{1}$ scenario, which was also the only determined case in the numerical analysis. 
Table 2 shows the internal energies obtained using the numerical model and determined using the analytical calculation (Pedersen and Zhang, 1998) for the collision velocities of $1.8 \mathrm{~m} / \mathrm{s}, 3.6 \mathrm{~m} / \mathrm{s}$ and $7.2 \mathrm{~m} / \mathrm{s}$. From these results, it can be observed that for the BWF and DWF scenarios with a velocity of $1.8 \mathrm{~m} / \mathrm{s}$ the analytical calculation presented lower values than those determined numerically with differences respectively between $13.3 \%$ and $15.8 \%$. and $8.6 \%$ and $14.8 \%$.

Table 2 Collision internal energy for different scenarios

\begin{tabular}{|c|c|c|c|c|c|c|c|c|}
\hline \multirow{3}{*}{ Scenario } & \multicolumn{8}{|c|}{ Internal Energy (MJ) } \\
\hline & \multicolumn{3}{|c|}{$v=1.8 \mathrm{~m} / \mathrm{s}$} & \multicolumn{3}{|c|}{$v=3.6 \mathrm{~m} / \mathrm{s}$} & \multicolumn{2}{|c|}{$v=7.2 \mathrm{~m} / \mathrm{s}$} \\
\hline & BWF & DWF & Analytical & BWF & DWF & Analytical & BWF & Analytical \\
\hline$\Delta \mathrm{T}_{1}$ & 6.0 & 6.1 & 5.2 & 20.4 & 19.0 & 23.0 & 218.0 & 268.0 \\
\hline$\Delta \mathrm{T}_{2}$ & 10.0 & 9.3 & 8.5 & 26.4 & 28.4 & 38.0 & -- & -- \\
\hline$\Delta \mathrm{T}_{3}$ & 12.3 & 11.8 & 10.3 & 47.0 & 40.5 & 45.6 & -- & -- \\
\hline$\Delta \mathrm{T}_{4}$ & 12.0 & 11.8 & 10.1 & 43.5 & 42.1 & 45.0 & -- & -- \\
\hline
\end{tabular}

For $3.6 \mathrm{~m} / \mathrm{s}$ and BWF scenario, unlike at $1.8 \mathrm{~m} / \mathrm{s}$, the energies determined analytically were higher except for $\Delta T_{3}$. The differences between the values remained between $3.0 \%$ and $43.9 \%$, and the greatest difference occurred in case 2 . For the DWF scenario, in all cases the internal energies calculated using the analytical expressions were larger than those obtained with finite elements, and with differences between $6.9 \%$ and $33.8 \%$, being the largest difference in case 2 . At the rate of $7.2 \mathrm{~m} / \mathrm{s}$ the analytically calculated energy was $22.9 \%$ higher.

Comparing the numerical and analytical results, for lower velocities the analytical method tends to underestimate the internal energy, and for higher velocities, for most of the cases, the energy is overestimated. The differences between the analytical and numerical results were between $3.0 \%$ and $43.9 \%$, which coincidentally occurred in the BWF case, with velocity of $3.6 \mathrm{~m} / \mathrm{s}$. Considering these comparisons and the velocity with which the results are obtained with the analytical method, it is evaluated that this procedure of calculation of internal energy may be very useful in the initial phases of design, being aware of its limitations.

Tables 3 and 4 summarize the values of the percentages of the total internal energies of each case distributed by the main components of the structure, for initial velocities $1.8 \mathrm{~m} / \mathrm{s}$ and $3.6 \mathrm{~m} / \mathrm{s}$, respectively. When the collision is between web frames (BWF) the energy absorbed by the side shell plating is greater for any of the draft differences. For collision directly on the web frames (DWF) at a velocity of $1.8 \mathrm{~m} / \mathrm{s}$ most of the energy is absorbed by the corresponding web frames. For a velocity of $3.6 \mathrm{~m} / \mathrm{s}$, even for direct collision on the web frames (DWF), the energies are higher on the side shell plating for all draft differences. Also, for both velocities, the longitudinal beams absorb less energy than the other two sets of elements, regardless the type of collision (BWF and DWF) and the scenario. With this study of energy distribution, it can be explicitly determined which set of structural components absorbs more energy during a collision. This information can be used to resize or to perform any other measure aiming to increase the structure strength against collision.

Table 3 Summary of the percentage of internal energy of main structural members $(\mathrm{v}=1.8 \mathrm{~m} / \mathrm{s})$.

\begin{tabular}{ccccccc}
\hline \multirow{2}{*}{ Scenario } & \multicolumn{2}{c}{ Side shell plating (\%) } & \multicolumn{2}{c}{ Web Frames (\%) } & \multicolumn{2}{c}{ Longitudinals (\%) } \\
\cline { 2 - 6 } & BWF & DWF & BWF & DWF & BWF & DWF \\
\hline$\Delta \mathrm{T} 1$ & 48.9 & 39.0 & 31.9 & 43.4 & 19.2 & 17.6 \\
$\Delta \mathrm{T} 2$ & 47.5 & 39.9 & 33.0 & 42.9 & 19.5 & 17.2 \\
$\Delta \mathrm{T} 3$ & 40.9 & 35.8 & 31.1 & 41.1 & 28.0 & 23.1 \\
$\Delta \mathrm{T} 4$ & 38.4 & 32.5 & 35.7 & 44.2 & 25.9 & 23.3 \\
\hline
\end{tabular}

Table 4 Summary of the percentage of internal energy of main structural members $(v=3.6 \mathrm{~m} / \mathrm{s})$.

\begin{tabular}{cllllll}
\hline \multirow{2}{*}{ Scenario } & \multicolumn{2}{c}{ Side shell plating (\%) } & \multicolumn{2}{c}{ Web Frames (\%) } & \multicolumn{2}{c}{ Longitudinals (\%) } \\
\cline { 2 - 7 } & BWF & DWF & BWF & DWF & BWF & DWF \\
\hline$\Delta \mathrm{T} 1$ & 52.9 & 54.6 & 30.5 & 30.5 & 16.6 & 14.9 \\
$\Delta \mathrm{T} 2$ & 52.4 & 41.8 & 17.8 & 27.3 & 29.8 & 30.9 \\
$\Delta \mathrm{T} 3$ & 50.4 & 46.6 & 25.9 & 29.4 & 23.7 & 24.0 \\
$\Delta \mathrm{T} 4$ & 48.8 & 46.4 & 26.7 & 30.3 & 24.5 & 23.3 \\
\hline
\end{tabular}


A criterion to be adopted in the design phase to determine the set of structural elements that absorb most of the collision energy should combine the effects of initial velocity, draft difference and localization of collision (BWF or DWF). In this work, the percentage average of the energies in each set of structural elements is proposed. The set that presents the highest average value is considered the most susceptible to absorb more energy in any collision scenario that may occur. The results of the collision analyses are presented in Tables 3 and 4 . For each set of elements 16 terms are added (eight cases for BWF and DWF). For the hull plates, web frames and longitudinal stiffeners the averages are respectively equal to $47.1 \%, 32.7 \%$ and $20.2 \%$. It is evident that, in this case, the side shell plating is the most affected structural part during a collision, and any planned measure to improve the performance of the structure will have a greater chance of success if this information is taken into account.

\section{ULTIMATE LONGITUDINAL BENDING STRENGTH OF FPSO}

\section{Structural Model}

The overall behavior of the FPSO structure subjected to sagging and hogging longitudinal bending moments before and after collision is analyzed here. The reduced numerical model included five web frames of the central tank and intact (Figure 12a) and three damaged hulls were considered. One damage resulted from the BWF collision of the PSV with a velocity of $3.6 \mathrm{~m} /$ sand case 2 (Figure 12b). The second damage the collision was BWF, the PSV velocity was $7.2 \mathrm{~m} / \mathrm{s}$ and case 1 (Figure 12c). The latter case was assumed to be an adaptation of the IACS (2014) Common Structural Rules for Bulk Carriers and Oil Tankers (Figure 12d). The geometries of the damaged structures were extracted from the previous collision analyses without considering the residual stresses and merged with the rest of the intact hull structure.

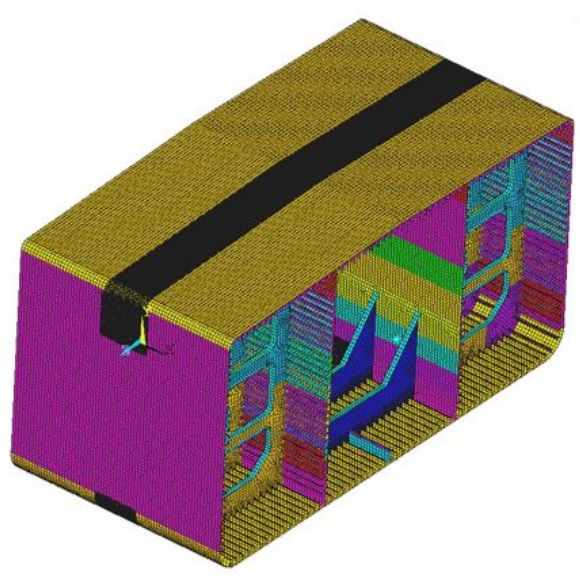

(a) Intact ship

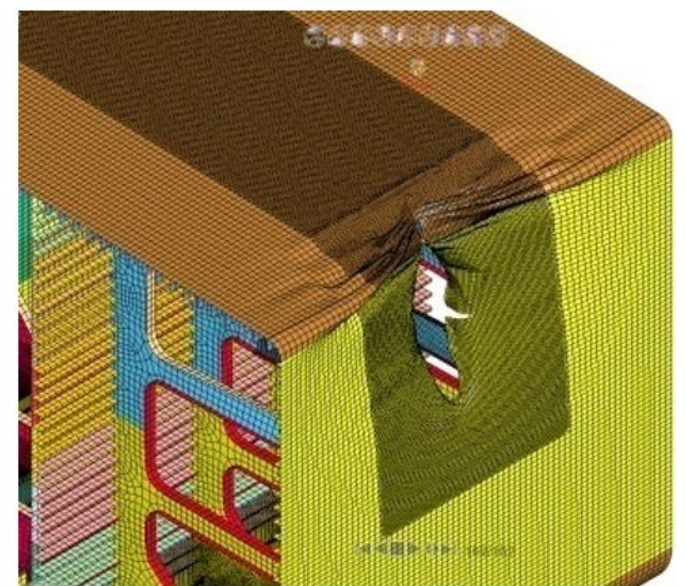

(c) Ship collided by a PSV ( $v=7.2 \mathrm{~m} / \mathrm{s})$

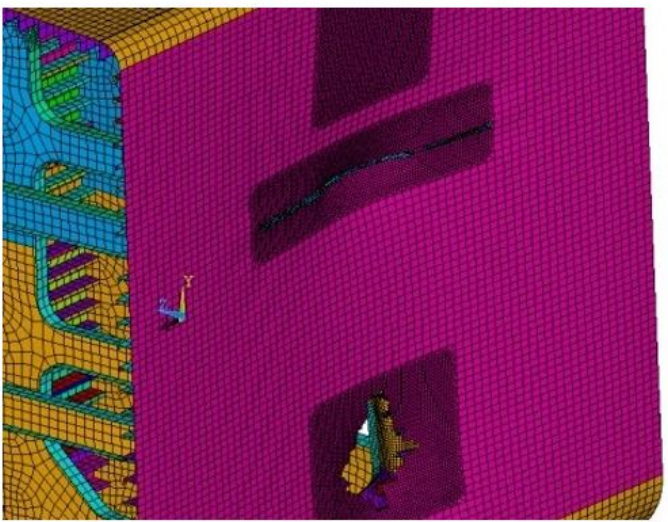

(b) Ship collided by a PSV ( $v=3.6 \mathrm{~m} / \mathrm{s})$

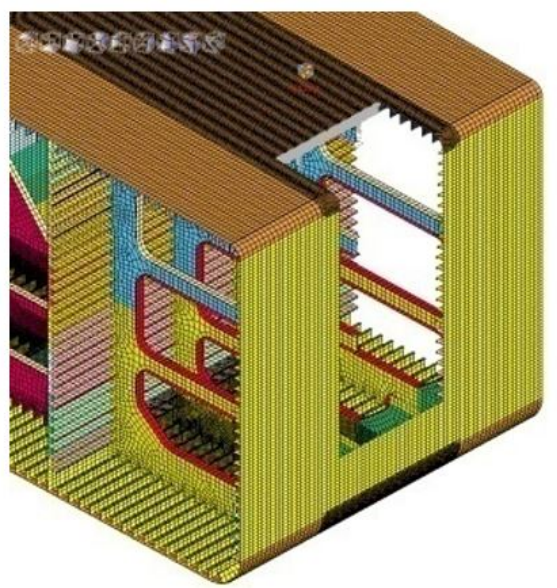

Ship collided by IACS

Figure 12: Models for global strength determination (a) Intact Ship (b) Ship collided by a PSV (v=3.6 m/s) PSV ( $v=7.2 \mathrm{~m} / \mathrm{s})(\mathrm{d})$ Ship collided by IACS

(c) Ship collided by a 
This standard describes the condition of damage in cases of collision and stranding, presenting the dimensions of damage on the side and bottom of the ship, for single and double hulls. For the simple hull the recommendation is to consider openings on the side and deck with lengths respectively equal to $0.75 \mathrm{D}$ and $\mathrm{B} / 16$ (corresponding to $20.85 \mathrm{~m}$ and $3.41 \mathrm{~m}$ ), where $D$ and $B$ are respectively the moulded depth and breadth. The width of the opening is not specified in IACS (2014) standard, and itwas adopted $9.0 \mathrm{~m}$, which approximately corresponds to the width where the greatest damage occurred in the case of PSV with initial velocity $7.2 \mathrm{~m} / \mathrm{s}$.

To minimize the boundary conditions effects due to the load application, the model is extended by a further web frame spacing on the fore and aft. To carry out the numerical structural analysis of the intact ship, initial geometric imperfections in the bottom and deck plates were added to the model. It was assumed that the geometric imperfections take the form of the first elastic buckling mode with amplitude as recommended by DNVGL-OS-C401, Ch2. Sec. 2E (DNV GL, 2017). A mesh sensitivity study was performed to ensure a good approximation of collapse and post-collapse responses at viable computational time. In the contact areas between the vessels and in the central region of the tank at the bottom and deck (see Figure 12) the elements are $50 \mathrm{~mm}$ long and $360 \mathrm{~mm}$ elsewhere.

\section{Ultimate longitudinal bending strength of the FPSO ship}

The behavior of the FPSO subjected to longitudinal bending is expressed by the relationship between the imposed bending moment and the curvature resulting from the hull deflection. This relationship can be achieved by imposing a sequence of rotational increments in the extreme sections of the model, determining for each of them the corresponding bending moment, assuming that the plane sections remain plane. The overall collapse of the ship's hull occurs when the bending moment versus curvature reaches its maximum value. Rigid elements are placed at the ends of the model to avoid undesirable deformations when the rotations are applied. In order to apply the rotation, the edge nodes are coupled to a "master" node situated on the neutral axis in the plane of longitudinal symmetry. In Figure 13 these nodes are indicated as points 1 and 2. The rotation of the "master" node of a given angle will promote the same rotation of all nodes attached to it. Since the nodes belong to the same cross-section, all nodes remain in the same plane after the rotation but they are free to move in the $x$ and $y$ directions and rotate around the $z$-axis. Angular increments for both sagging and hogging were equal to $0.0035 \mathrm{rad}$.

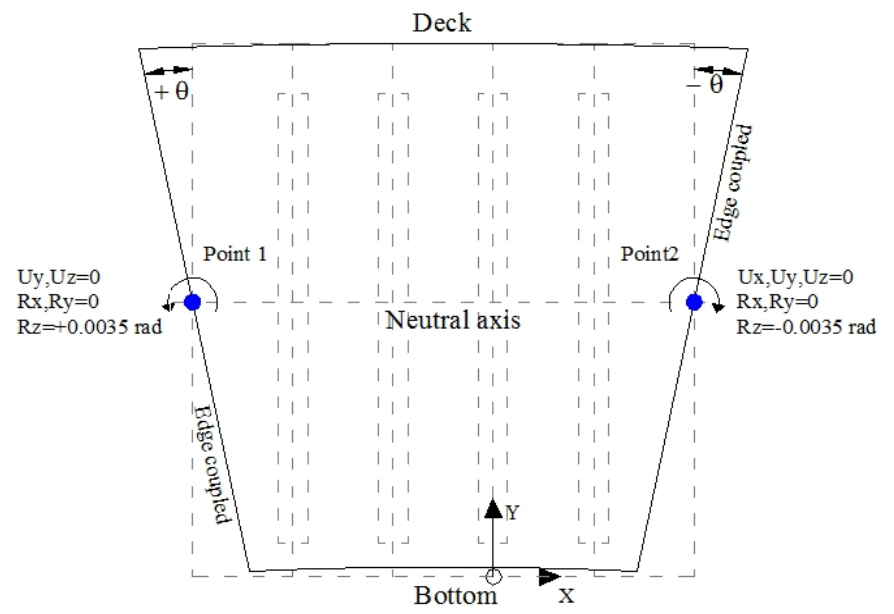

Figure 13: Side View-Hogging

For each of the damage cases, sagging and hogging bending analyses were performed to evaluate structural collapse and post-collapse. In these analyses, other internal and external loading in the ship's tanks were not introduced. The maximum allowed bending moments in the intact condition (Mti) and damaged condition (Mt) for the cases of sagging and hogging determined using the finite element procedure described above were compared with those calculated on the basis of the Common Structural Rules for Bulk Carriers and Oil Tankers, IACS (2014).

\section{RESULTS}

In Figures 14 and 15 the bending moment curves of the FPSO structure for the sagging and hogging cases, respectively, are presented. In both graphs, it can be seen that the differences between the curves are small in the linear elastic regime. In the case of Ship collided by PSV (velocity of $3.6 \mathrm{~m} / \mathrm{s}$ ) submitted to sagging (Figure 14) and 
hogging (Figure 15), there was not much variation in the ultimate bending moment for both cases when compared to the intact ship, but the post-collapse behavior was quite different. The bending moment versus curvature curve (Figure 14) in the event ship collided by PSV with initial velocity $7.2 \mathrm{~m} / \mathrm{s}$ shows that near curvature $9.0 \times 10^{-5} \mathrm{~m}^{-1}$ there was loss of strength, and with an increasing curvature the momentum increases at low rate, and tends to remain constant starting at the curvature of $12 \times 10^{-5} \mathrm{~m}^{-1}$ but with a bending moment lower than for an intact FPSO. For the same event collision the ultimate hogging bending moment (Figure 15) is much lower than for intact hull at a curvature of $9.0 \times 10^{-5} \mathrm{~m}^{-1}$. After the maximum bending moment, there was a soft drop and then the bending moment remained nearly constant. Considering the idealized damages in the FPSO proposed by IACS (2014), either for sagging or hogging moments, the bending moment curves versus curvatures presented small variations in relation to the intact ship.

Figures 14 and 15 were produced with a damage preconized by IACS (2014), but with a modification in the opening depth on the FPSO deck, which increased from $3.41 \mathrm{~m}$ to $6.0 \mathrm{~m}$ because it approximately corresponds to the depth of the major damage produced on the FPSO deck by the PSV with velocity velocity of $7.2 \mathrm{~m} / \mathrm{s}$. For both sagging and hogging moments (Figures 14 and 15), in the elastic phase, the curves for this case presented a strength slightly lower than that of the intact ship and very similar to the one assuming collision with velocity of $7.2 \mathrm{~m} / \mathrm{s}$. The maximum bending moments were slightly lower than for the intact ship and the ship collided with velocity of $3.6 \mathrm{~m} / \mathrm{s}, \mathrm{with}$ the corresponding curvatures being very similar.

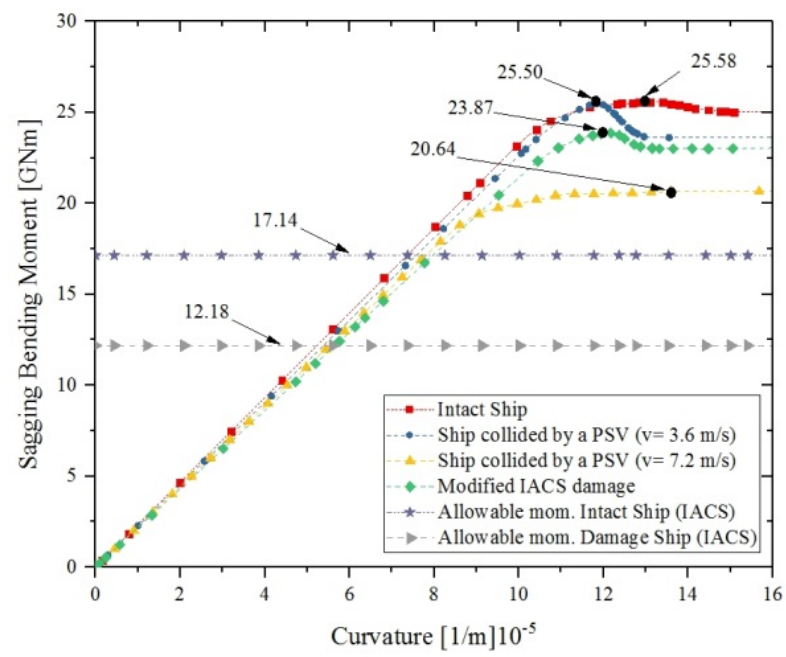

Figure 14: Sagging bending moment vs curvature

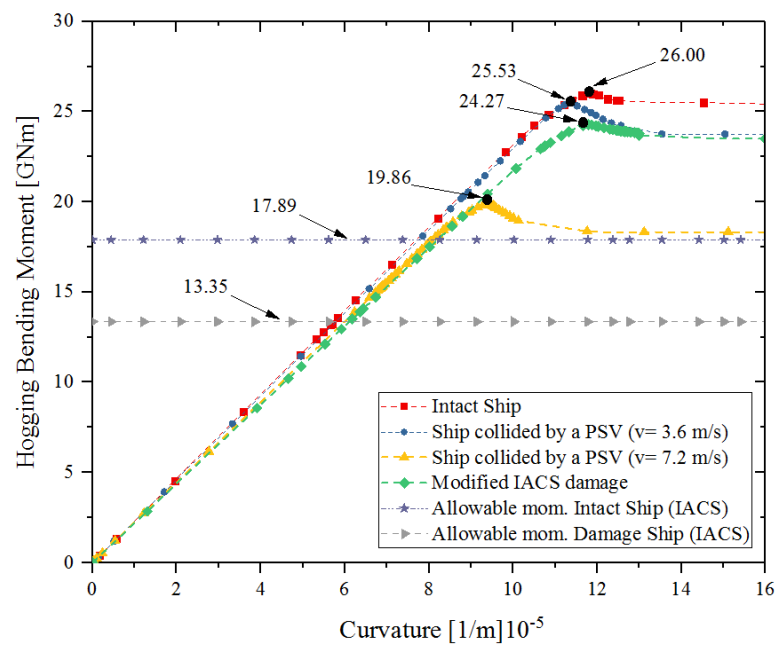

Figure 15: Hogging bending moment vs.curvature

As a basis for comparison, the peak moment values for intact and damaged FPSO determined by the formulation proposed by IACS (2014) for the sagging and hogging cases are illustrated in Figures 14 and 15, respectively. The maximum values for all analyzed cases are summarized in Table 5 . The ratios maximum bending moment by the 
allowable IACS bending moment showed for all damaged cases values greater than the ratios for an intact FPSO. This result indicates that the FPSO even with severe damages still presents good residual strength.

Table 5 Summary of the ultimate bending moment of the ship's structure

\begin{tabular}{cccccc}
\hline & & Max. Bending Moment (GN.m) & \multicolumn{2}{c}{ Ratio Max. Moment to Allowable } \\
Moment
\end{tabular}

From these analyses, the damage conceived by the modified IACS (2014) reduces the value of the maximum bending moment for the intact FPSO by only $6.7 \%$ in both sagging and hogging conditions. Higher strength loss occurs for the PSV collision with velocity $7.2 \mathrm{~m} / \mathrm{s}$, where the maximum sagging moment was $19.3 \%$ lower than the intact case and hogging was $23.6 \%$ lower. The PSV collision with the PFSO at $v=7.2 \mathrm{~m} / \mathrm{s}$, whose damage inside the tank is shown in Figure 16a was more deleterious to the residual strength of the FPSO than the idealized damage of the modified IACS (2014), even though it does not present such a large opening in the hull. In Figure 16b the hull aperture is shown for the modified IACS idealized damage (2014). This greater strength loss can be explained by the large deformation extension produced by the collision in the reinforcing elements of the deck plating (longitudinals and deck girder) and side plating (longitudinals and web frames), as well as the platings themselves. In Figure 16a in addition to two central web frames, two side web frames also suffer significant damages. Outside the central area, the sheer strake, deck stringer, side and deck plates, together with their respective longitudinals are highly affected.

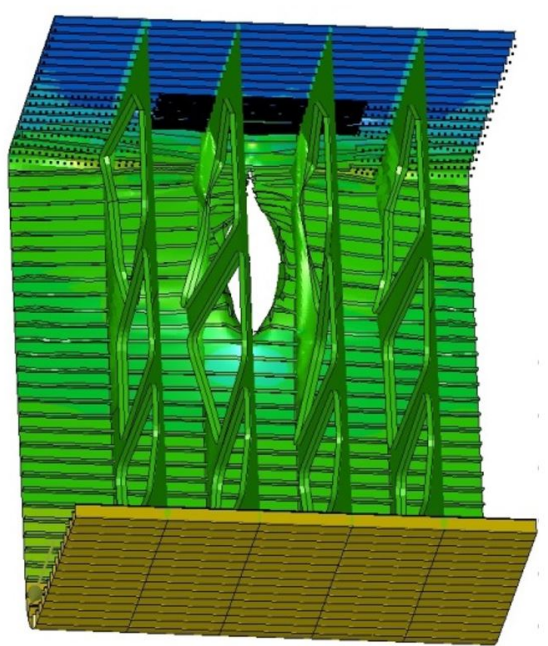

(a)

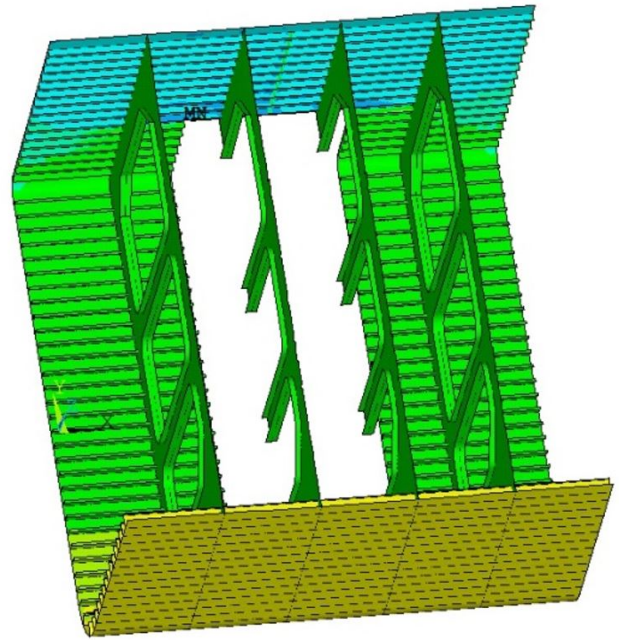

(b)

Figure 16: (a) Tank collided by PSV with $v=7.2 \mathrm{~m} / \mathrm{s}$. (b) FPSO tank with idealized IACS damage

\section{CONCLUSION}

It was initially shown in this paper the development of a finite element model for the simulation of collision between ships. The numerical simulation of an experimental collision test performed by other authors validated this model. Numerical and experimental results were compared in terms of collision force and internal energy versus penetration depth curves. Using the simulations of this collision test, some parameters were defined, which allowed establishing the numerical methodology capable to reproduce with good fidelity this phenomenon. 
It is possible to observe that the Peschmann criterion is the one that presented less variation with the mesh size. The GL criterion presented better results only for the more refined meshes. The regularity of error percentage of the Peschmann criterion for the mesh range between 25 and $100 \mathrm{~mm}$ was better than presented by the other two failure criteria. Some recommendations for futures works about this validation would be to perfom a deeper study of the influence of strain rate, hydrodynamic force and distortions distribution in the collapse of the structure.

Then, the developed model was applied to the collision simulation of a PSV and a single-hull FPSO converted from a Very Large Crude Carrier (VLCC). The PSV bow structure was considered rigid. For the analyses, different collision scenarios were considered, including collision between web frames (BWF) and directly on web frame (DWF), with a $90^{\circ}$ angle; four different drafts differences $(\Delta T)$; PSV initial collision velocities of $1.8 \mathrm{~m} / \mathrm{s}$ and $3.6 \mathrm{~m} / \mathrm{s}$ applied to all combinations of previous cases; increased PSV mass and velocity of $7.2 \mathrm{~m} / \mathrm{s}$ considering only one draft difference and collision between web frames. According to the analyses, it was observed that at a PSV velocity of $1.8 \mathrm{~m} / \mathrm{s}$ the damages are relatively light, with no fracture of the FPSO hull and the deformation internal energy varied between $6.0 \mathrm{MJ}$ and $12.3 \mathrm{MJ}$. With velocities of $3.6 \mathrm{~m} / \mathrm{s}$ and $7.2 \mathrm{~m} / \mathrm{s}$, the damages were considered to be severe, with FPSO hull fracture in all analyzed scenarios. For the PSV initial velocity of $3.6 \mathrm{~m} / \mathrm{s}$, the deformation internal energy ranged between $19.0 \mathrm{MJ}$ and $47.0 \mathrm{MJ}$ and in the case of $7.2 \mathrm{~m} / \mathrm{s}$ the energy was $218 \mathrm{MJ}$. The highest deformation internal energy occurred in the cases where the PSV draft were equal to the design draft $\left(T_{1 \max }\right)$ generating the lowest drafts differences between the ships ( $\Delta T_{3}$ and $\Delta T_{4}$ ). The analytical method proposed by Pedersen and Zhang (1998) reasonably approximated the numerical results proving useful for estimation in the early design stages, but their results underestimated the internal energy for the cases with collision velocity of $1.8 \mathrm{~m} / \mathrm{s}$ and overestimated it for the other two higher velocities.

In order to trace a more detailed picture of the effects of a collision on the FPSO structural elements, they were divided into side shell plating, web fames and longitudinals, and for each one of these groups the deformation internal energy and its total were determined. The knowledge of the internal energy for groups of elements in a large number of collision scenarios does not define per se which group of elements are susceptible to absorbing more energy. In this article, it is proposed a criterion that takes into account the combination of as many collision scenarios as possible by averaging the percentages of the energy in each set of elements. The group of structural elements that presents the highest average energy percentages is identified as the one that is likely to absorb more energy. This information could be used in initial design phases to improve the collision structure crashworthiness performance or take decisions to protect a structure by mitigating the effects of such accidents. In the case of the FPSO studied, the structural elements that presented the greatest propensity to absorb more energy were the hull plating.

The overall strength of the FPSO was determined considering the intact hull, damaged by PSV collisions with velocity of $3.6 \mathrm{~m} / \mathrm{s}$, in the BWF scenario with $\Delta T_{2}$ and with velocity of $7.2 \mathrm{~m} / \mathrm{s}$, BWF scenario with $\Delta T_{1}$, and with a damage model proposed by the IACS with modification. The maximum bending moments of sagging and hogging of the FPSO for the intact case are very close to those of the considered damaged, except for the damages caused by an augmented PSV collision velocity of $7.2 \mathrm{~m} / \mathrm{s}$.

The ratios of maximum moments with damages by the admissible moment of the IACS show that these ratios are greater than those of the intact FPSO, indicating that the FPSO maintains an acceptable level of safety according to the IACS, provided that it is guaranteed that the permissible moment is not exceeded.

It was also observed that in the case of single hull FPSO the dimensions of the idealized damages preconized by the IACS seem to overestimate the remaining strength of the struck vessel when the collision occurs with heavier and faster vessels. Even with the damage of the modified IACS, i.e. with an increase in deck opening to simulate the damage, the maximum bending moment was greater than that calculated with the damage produced by the PSV with initial speed equal to $7.2 \mathrm{~m} / \mathrm{s}$. This means that the damage proposed by the IACS leads to a prediction of residual strength greater than that determined for the PSV collision with a speed of $7.2 \mathrm{~m} / \mathrm{s}$.

\section{Acknowledgments}

The authors acknowledge the support from the National Council for Scientific and Technological Development (CNPq) and National Agency of Petroleum, Natural Gas and Biofuels (ANP).

Author's Contributions: Conceptualization, JL Martinez, JCR Cyrino and MA Vaz; Methodology, JL Martinez; Investigation, JL Martinez; Formal analysis, JL Martinez; Writing - original draft, JL Martinez; Writing - review \& editing, JL Martinez, JCR Cyrino and MA Vaz; Validation, JCR Cyrino and MA Vaz.

Editor: Rogério José Marczak. 


\section{References}

ANSYS Inc. (2016) Manual, Canonsburg, PA, USA.

Calle, M.A.G., Alves, M., (2015). A review-analysis on material failure modeling in ship collision. J. Ocean Eng. v. 106, 20-38.

Carlebur, A.F., (1995). Full-scale collision test. Saf Sci;19:171-8

DNV GL (2017). Standard DNV-OS-C401, Fabrication and Testing of Offshore Structures, Offshore Standard. DetNorske Veritas.

Ehlers, S., Broekhuijsen, J., Alsos, H.S., Biehl, F, Tabri, K., (2008). Simulating collision response of ship side structures: A failure criteria benchmark study. Int. Shipbuild. Prog. 55, pp. 127-144.

Ehlers, S., (2011). A review of collision and grounding damage assessment methods. Marit. Systems \& Ocean Technology 6, No 1, pp. 5-15.

Hagen, S.A., (2018). Damage Assessment of Sevan 1000 FPSO Subjected to Impacts from Shuttle Tankers. Norwegian University of Science and Technology, M.Sc. Dissertation.

Hogström, P., (2012). RoPax ship collision - a methodology for survivability analysis. Department of Shipping and Marine Technology, Chalmers University of Technology, Ph.D. Thesis.

Hussein, A.W. and Guedes Soares, C., (2009). Reliability and residual strength of double hull tankers designed according to the new IACS common structural rules. Ocean Eng. v. 36, 1446-1459.

IACS, (2014). Common Structural Rules for Bulk Carriers and Oil Tankers, International Association of Classification Societies, London, UK.

Kim, D.K., Kim, B.J., Seo, J.K., Kim, H.B., Zhang, X. and Paik, J.K., (2014). Time-dependent residual ultimate longitudinal strength - grounding damage index (R-D) diagram. Ocean Eng. v. 76, 163-171.

Kitamura, O., (2002). FEM approach to the simulation of collision and grounding damage. Mar.Struct.15,403-428.

Lehmann, E., Peschmann, J., (2002). Energy absorption by the steel structure of ships in the event of collisions. Mar. Struct. v. $15,429-441$.

Liu, B., Villavicencio, R., Zhang, S., Guedes Soares, C., (2017). Assessment of external dynamics and internal mechanics in ship collisions. J. Ocean. Eng. v. 141, 326-336.

Luís, R.M., Hussein, A.W., Guedes Soares, C., (2007). On the effect of damage to the ultimate longitudinal strength of doubles hull tankers.Proc. of 10thIntSymp on Practical Design of Ships and Other Floating Structures, Houston, Texas, USA.

Martinez, J.L., Cyrino, J.C.R., Vaz, M.A., (2017). Continuum damage mechanics applied to numerical analysis of ship collisions. Mar. Struct. v. 56, 206-236.

Minorsky, V.U., (1959). An analysis of ship collision with reference to protection of nuclear. J. Sh. Res.3, pp. 1-4.

Ozguc O., (2019). Structural damage of ship-FPSO collisions, Journal of Marine Engineering \& Technology, 18:1, 1-35, DOI: 10.1080/20464177.2017.1359387.

Paik, J.K., Kim, D.K., Park, D.H., Kim, H.B., Kim, M.S., (2012). A new method for assessing the safety of ship damaged by grounding. Int. J. Marit. Eng., 154(A1), 1-20.

Pedersen, P.T., Zhang, S., (1998). On impact mechanics in ship collisions. Mar. Struct. 11, 429-449.

Peschmann, J., (2001). Energy absorption computations of ship steel structures under collision and grounding. Ph. D. Thesis, Technical University of Hamburg, Germany.

Pill, I., Tabri, K., (2009). Finite element simulations of ship collisions: A coupled approach to external dynamics and inner mechanics. Ships and Offshore Structures, v.6, pp.59-66.

Prabowo, A.R., Bae, D.M., Sohn, J.M., Cao, B., (2016). Energy behavior on side structure in event of ship collision subjected to external parameters. Heliyon 2, e00192. https://doi.org/10.1016/J.HELIYON.2016.E00192

Safety and Shipping Review, (2017). An annual review of trends and developments in shipping losses and safety, http://www.agcs.allianz.com/assets/PDFs/Reports/AGCS_Safety_Shipping_Review_2017.pdf/ (accessed in31.01.2018). 
Silva G.G. (2001). Post-collision residual strength of stiffened panels in FPSO. M. Sc. Dissertation (in Portuguese), Federal University of Rio de Janeiro, Brazil.

Sterndorff, M.J. P (1996). Ground experiments on soft bottoms. J Mar Sci Technol;1:174-81.

Törnqvist, R., (2003). Design of crashworthy ship structures. Technical University of Denmark, Ph.D. Thesis.

Vredeveldt, A., Feenstra, E., (2001). Crashworthy side structures for improved collision damage survivability of coasters and medium sized Ro-Ro cargo ship, Report GRD1-1999-10566, TNO/UNI, Netherlands.

Wevers, L.J., Vredeveldt, A.W., (1999). Full scale ship collision experiments, 1998.TNO-report 98-CMC-R0359, TNO, Delft.

Woisin G., (1979). Design against Collision. Proc 3rd Int Conf Collis Groundind Ships:27-73.

Yamada, Y., Ogawa, Y., (2011). Study on the residual ultimate longitudinal strength of hull girder of a bulk carrier against moment after ship collision. Advances in Marine Structures, 429-436. Eds. Guedes Soares\& Fricke, Taylor \& Francis Group London.

Yamada, Y., (2014). Numerical study on the residual ultimate strength of hull girderof a bulk carrier after ship-ship collision. Proceedings of the ASME 2014 33rd International Conference on Ocean, Offshore and Arctic Engineering June 8-13, 2014, San Francisco, California, USA.

Zhang, L., Ed, E., Bruhms, H., (2004). Approval Procedure concept for alternative arrangements. In: Proceedings of theThird International Conference on Collision and Grounding of Ship, Japan. 84-97. 